\title{
Interpretation of Hyperchromic Nerve Cells

\author{
RELATIVE SIGNIFICANCE OF THE TYPE OF FIXATIVE USED, \\ OF THE OSMOLARITY OF THE CYTOPLASM AND THE \\ SURROUNDING FLUID IN THE PRODUCTION \\ OF CELL SHRINKAGE'
}

\author{
REINHARD L. FRIEDE \\ Mental Health Research Institute, University of Michigan, \\ Ann Arbor
}

Contradictory opinions have been expressed as to the significance of the hyperchromic, shrunken cells (Flesch, 1887) which are often found in normal animal brains and, under certain conditions, in human material. Nissl (1896) considered hyperchromic cells artifacts; Cajal ('09) resting cells; Dolley ('10) to represent initial stages of fatigue; Fortuyn ('27) functional stages; Einarson (' $49 \mathrm{a}$ and b) hyperactive cells; Scharrer ('33, '37, '38) mechanical artifacts; and Cammermeyer ('60b, '61) products of postmortem traumatization and consequent fixation. Furthermore, many investigators reported on these cells in experimental and human pathological material, interpreting them as pathological changes. Numerous references are found in the review by Miller (49) and in Cammermeyer's ('60, a and b, '61) recent papers.

Many such painstakingly executed studies indicate the conditions under which hyperchromic cells can be produced or avoided. Few, however, offer clues as to the precise mechanism responsible for the volume change. A cell filled with, and surrounded by, fluid cannot simply "collapse" (Cammermeyer, '60b) unless there is either damage to the membrane with outflow of cytoplasm or a shift of the osmotic equilibrium. Likewise, there is no known colloid which shrinks to a fraction of its volume (Cotte, '57; Picard and Cotte, '57) upon minimal mechanical stimulation but retains its volume if not stimulated. Osmotic changes during fixation have been studied to a considerable extent (Fortuyn, '24, '27; Koenig, Groat, and Windle, ' 45 ; and others), but a generalization based on this data is not possible unless one knows whether and to what extent the cell membrane is affected by the fixative. The latter question cannot be clarified in a complex tissue; thus, the sample experiments with red blood cells reported below were thought necessary to investigate differences in the mode of action of the fixative on the cell membrane. There were indications that hyperchromasia of nerve cells and crenation of erythrocytes were closely related phenomena.

This study, thus, represents an effort toward a better understanding of the mode of action of fixatives, the significance of mechanical damage to the tissue, and the interaction of these factors in the production of hyperchromic, shrunken cells. A variety of experiments was used to analyze the complex interactions of osmotic changes, dependent upon the osmotic state of the cell's cytoplasm, the osmotic concentration of the surrounding fluid, and the type of fixation used.

\section{METHODS AND MATERIAL}

Total number of experiments. Each experiment on blood fixation was repeated at least five times as was each experiment on the rat brain. In addition, almost as much rat brain data was available from a preliminary series of similar experiments.

\footnotetext{
1 This study has been initiated as a project on mechanical cell damage during the author's term at the Aero Space Medical Laboratories, Wright Air Development Division, Dayton, Ohio, It was supported partially by U. S. Public Health Grant $B-3250$ the technical assistance of Albert Vossler is acknowledged.
} 
For every experiment reported, the observations were consistent in all the brains or specimens respectively. Rats were used because the distribution of the changes resulting from local pressure was evaluated more readily in a flat cortex than in a gyrencephalic brain,

A. Sample experiments using erythrocytes. Fresh rat blood was added dropwise to various fixatives under slight, continuous agitation. After completion of fixation, the cells were centrifuged, prepared as a smear, and stained with hematoxylin-eosin and other stains.

B. Experiments on brain tissue. Rats were killed by a blow to the upper thoracic cord, carefully avoiding any impact to the head. Rats used for perfusion fixation were killed by sudden exposure to natural gas. The cerebral hemispheres were exposed as quickly as possible, scrupulously avoiding pressure or mechanical damage to the surface of the brain. Approximately two minutes elapsed between death and exposure of the brain. Immediately following exposure of the brain, a wedgeshaped instrument was pressed on the right hemisphere four times. The length of the wedge was $7 \mathrm{~mm}$ and its inclination $80^{\circ}$. This wedge was mounted on a springtonometer and the exact force applied was recorded. The pressures applied to the wedge were either 28 or 40 grams; and effort was made to compare the intensity of the pressure with the intensity of histological changes. Following the application of pressure, a recorded interval ranging from one to five minutes was permitted to elapse before exposure of the brain to the fixative. Then the head with the exposed brain in situ was suspended in an ample volume of fixative. The tissues were removed from the skull after the completion of the fixation (several days for formalin).

In the experiments 11,13 , and 14 , the animals were fixed by perfusion from the heart; the method of exposure of the brain, the application of pressure, and the timing were identical with those of the other experiments. Preceding perfusion, blood was removed from the vessels by a brief rinse with balanced Acacia solution (Koenig, Groat, and Windle, '45).

The term "formalin" as used in the text refers to $10 \%$ neutral formalin; the various additives are listed in the text. Material from trial experiments using perfusion with Carnoy's fluid was discarded since, in our hands, satisfactory fixation by perfusion with Carnoy's fluid was impossible. All material was embedded in paraffin under the same conditions; sections $10 \mu$ thick were stained with hemotoxylin-eosin.

\section{RESULTS}

First part of the experiment: Model experiments using rat erythrocytes

Experiment 1. "Fixation in isotonic solution preserves the normal shape of erythrocytes." Blood was fixed in isotonic $10 \%$ formalin $(0.9 \% \mathrm{NaCl})$; the erythrocytes retained their normal shape. Neither crenation nor swelling was observed.

Experiment 2. "Hypertonic medium produces crenated erythrocytes." Sodium chloride was added to the blood to yield a final concentration of $10 \%$. This blood was fixed in formalin containing $10 \%$ sodium chloride. The erythrocytes showed a marked crenation resulting from osmotic shrinkage.

Experiment 3. "Osmotic crenation does not develop in fixed cells." Blood was fixed for several hours in isotonic formalin (as in experiment 1) and then was exposed to $10 \%$ sodium chloride. Crenation did not develop in the fixed erythrocytes.

Experiment 4. "Crenation develops during fixation in hypertonic formalin." Blood was fixed in formalin with $10 \%$ sodium chloride. The majority of the cells showed crenation, but the extent of crenation was somewhat less than in experiment 2.

Comments on experiments 1 through 4. Experiments 1 to 3 showed that hypertonic solutions caused crenation in the unfixed, but not in the fixed, erythrocytes. Experiment 4 indicated a competition between the rate of osmotic changes and the rate of fixation of the cell. Formalin did not destroy the selective permeability of the cell membrane of the erythrocyte, and thus permitted the development of osmotic shrinkage (crenation) before the cells were fixed. Experiment 3 showed that crenation does not develop after fixation of the cell. In view of these conclusions, 
it seemed important to estimate the rate of osmotic shrinkage of red blood cells.

Experiment 5. "Osmotic shrinkage (crenation) of cells is extremely rapid." Heparinized fresh rat blood, diluted in a slightly hypotonic solution, showed no crenated cells under the microscope. After this observation was made, the coverslip was quickly lifted, a drop of $10 \% \mathrm{NaCl}$ was added, stirred, and the coverslip was put back in place. This procedure was performed as rapidly as possible. The shortest time between application of the hypertonic solution and the refocussing of cells was three seconds. At this time, excessive crenation of erythrocytes was already present; it increased little, if any, in the following minutes. Lifting of the coverslip without addition of hypertonic medium did not produce crenation. This demonstrated that osmotic shrinkage of red blood cells could develop in three seconds or less.

Experiment 6. "Rapid fixation does not prevent development of crenation." Blood was fixed in hypertonic $9 \%$ sulfosalicylic acid (Sannomiya, '26) or in 4\% phosphotungtic acid (Rawitz, '08). Fixation in these fluids occurred extremely fast, upon contact, as indicated by a rapid change of color. Yet, smears showed an abundance of excessively crenated cells.

Experiment 7. "Fixatives which destroy the cell membrane cause hemolysis of erythrocytes." All the components of Carnoy's fixative (absolute alcohol, chloroform, acetic acid) are known to attack the lipids of cell membranes. One would not expect to observe osmotic changes following exposure to such a fixative. Fixation of blood in Carnoy's solution, however, resulted in instant hemolysis instead of fixation of the cells. Histological study of the centrifugated material showed no traces of cell membranes or cell structures. Fixation in 5\% trichloracetic acid (Heidenhein, '05) with $\mathrm{NaCl}$ also produced hemolysis. (Sodium chloride was added to produce excessive hypertonicity, thus excluding osmotic rupture as a cause of hemolysis.) Fixation in $80-95 \%$ alcohol (without added chloroform and acetic acid) resulted in fixation of cells, showing normal shape, slight shrinkage, but no crenation.
Thus, Carnoy's solution evidently destroyed the membrane of freely suspended cells faster than it could precipitate the stroma. The results obtained with the (highly corrosive) trichloracetic acid helped to exclude osmotic rupture as a cause of hemolysis. Alcohol without chloroform and acetic acid was less damaging to cell membranes and thus permitted fixation of the cells before destruction of their membranes was complete.

\section{CONCLUSIONS TO PART ONE}

These experiments indicated that osmotic shrinkage of erythrocytes could take place during exposure to the fixative, provided that the fixative did not destroy the cell membrane. Formalin evidently preserved cell membranes and permitted osmotic shrinkage of cells during fixation if the fixative was hypertonic. If the fixative was isotonic, the cells were preserved in their original shape. Osmotic shrinkage of erythrocytes developed extremely rapidly; that is, in three seconds or less. Fixatives which damaged the cell membrane produced hemolysis of the freely suspended erythrocytes. If osmotic changes during fixation are to be minimized, the capacity of the fixative to destroy the cell membrane is more important than the precipitating action of the fixative; since, when the membrane is preserved, osmotic changes precede fixation of the cell. This is true even when fixation is very rapid, (upon contact). In all of these experiments with erythrocytes, there was some variation of shrinkage among individual erythrocytes, suggesting a variance of the osmolar concentration ${ }^{2}$ of the cytoplasm.

\section{Second part of the experiment using brain tissue: Relationship between cell damage, osmotic changes, and the type of fixative}

Introduction. The following experiments applied the experiences from Part I to experiments in brain tissue. In addition, normal nerve cells were compared with cells slightly damaged by controlled pressure to a confined region of the cerebral cortex; thus the effect of the fixative on the normal cell population could be com-

2 Osmolar concentration: The total osmolar concentration of a fluid is the concentration of all osmotically active solutes in the fluid. 
pared with its effect on the cells exposed to local pressure; these cells will be referred to as "damaged cells." The following experiments will show that damaged cells behaved as if the osmolar concentration of their cytoplasm was lower than that of normal cells, rendering them more susceptible to osmotic shrinkage. This concept outlines the scope of possible interactions of osmolarity of the fixative, osmolarity of the cytoplasm, and the type of action of the fixative.

Experiment 8. "The volume of formalin-fixed nerve cells depends on the osmolar concentration of the formalin." This relationship has been demonstrated extensively by Koenig, Groat, and Windle ('45) who found shrinkage of nerve cells following perfusion of the brain with hypertonic formalin, and swelling of the cells following perfusion with hypotonic formalin. Since our observations agreed with this data, a quotation from the paper will suffice.

Experiment 9. "Cells which were osmotically shrunken or swollen before exposure to Carnoy's fixative were preserved in their respective state." Exposed brains (see Material and Methods) were immersed in either distilled water or a $9 \%$ solution of sodium chloride for periods ranging from five minutes to one hour; following exposure to these fluids, the brains were fixed in situ in Carnoy's fixative.

The brains exposed to distilled water showed a marked swelling and ballooning of all nerve cells and their apical dendrites (fig. 1). Brains exposed for a short period to $9 \% \mathrm{NaCl}$ showed excessive shrinkage of the cytoplasm of nerve cells. The shunken apical dendrites were visible over great distances as darkly stained corkscrew-shaped filaments. There was also excessive shrinkage of the nuclei of nerve cells. Prolonged exposure resulted in grotesque distortion and autolytic changes of the cells in the superficial parts of the tissue.

Experiment 10. "Local pressure produces shrunken cells in tissue fixed with isotonic formalin." Following local application of pressure (see Material and Methods), brains were fixed in isotonic formalin ( $0.9 \%$ sodium chloride). Histo- logically, the site of application of pressure was clearly recognizable as a large area in which almost all the nerve cells were markedly shrunken and hyperchromic (fig. 2). Some shrunken cells were also observed in other regions with unintended damage such as in the parasagittal region (removal of falx) and in the opposite hemisphere, where the temporal cortex had pressed against the bone. The number of hyperchromic cells increased with the length of the interval between the application of the pressure and the fixation.

Experiment 11. "Fixation by perfusion with isotonic gum-acacia formalin $(0.9 \%$ $\mathrm{NaCl}$ ) shows changes similar to those observed in experiment 10." The changes, however, were less extensive, thus supporting the view that the interval between application of pressure and fixation influenced the extent of development of shrunken cells. There were fewer shrunken cells in the perfused brains than in experiment 10 , in which the exposure to formalin was delayed by its diffusion into the deeper portions of brain tissue. If the perfusion was delayed for 20 to $30 \mathrm{~min}$ utes, many shrunken cells were found at the site of application of pressure similar to experiment 10 .

Experiment 12. "Fixative in hypertonic formalin causes shrinkage of both normal and damaged cells." Following pressure, the brains were fixed by immersion in $10 \%$ formalin with $9 \%$ sodium chloride: The entire cortical cell population showed severe shrinkage (fig. 3 ). The site of application of pressure could not be identified since there was no morphological feature distinguishing the damaged cells, except the vague impression of slightly more shrinkage. Glial nuclei were also shrunken (fig. 3), a condition which was not observed in fixation with isotonic formalin (fig. 2).

Experiment 13. "Perfusion with hypertonic formalin ( $9 \%$ sodium chloride) following application of pressure produces results similar to immersion in hypertonic formalin." The extent of shrinkage of nerve cells was somewhat less with perfusion. The area of application of pressure could be recognized by a slight gradient of shrinkage between the damaged 
cells and the adjacent normal cells. The area containing shrunken cells was not delineated as sharply as following fixation in isotonic formalin (experiment 10) since there was a gradual transition between the extent of shrinkage of normal and damaged cells.

Experiment 14. "Perfusion with hypotonic formalin reduces the extent of shrinkage of damaged cells." Perfusion of the brain with hypotonic formalin ( $10 \%$ formalin without sodium chloride) following application of pressure produced swelling of the normal cell population as observed in experiment 8 . The cells at the site of application of pressure were still shrunken, but somewhat less (fig. 4) than when perfused with isotonic gum-acacia formalin (fig. 2). After the latter, all shrunken cells appeared as compact, darkly stained structures with their nuclei barely distinguishable from the cytoplasm. In the present experiment, nucleus and cytoplasmic structures were readily distinguishable in many of the shrunken cells.

Experiment 15. "Damaged cells swell less than normal cells if exposed to distilled water." An effort was made in this experiment to expand the damaged cells by an extremely hypotonic fixative. After application of pressure, the brains of five animals were exposed to distilled water for 5 to 30 minutes, followed by fixation in $3 \%$ formalin. Even under this extreme condition, the $3 \%$ formalin was still hypertonic and produced shrinkage (Fortuyn, '27) of the damaged cells; this material had to be discarded as inconclusive. When, in five other animals, exactly the same experiment was repeated except for fixation in Carnoy's fluid, there was marked swelling of the entire normal cell population as in experiment 9. The cells at the area of pressure were characterized by markedly less swelling than that seen in normal cells. There were none, or extremely few, shrunken cells.

Experiment 16. "Addition of acetic acid to isotonic formalin prevents shrinkage of cells." This experiment was to demonstrate that the production of shrunken cells was not due to a specific property of the formalin. Following exposure to pressure, brains were fixed in isotonic formalin containing $10 \%$ glacial acetic acid. The nerve cells in such brains closely resembled those in brains fixed in Carnoy's fixative (experiment 17, below). There were no shrunken cells outside of the area of pressure. At the site of pressure, the number and the area of distribution of shrunken cells were much smaller (fig. 5) than in specimens fixed in isotonic formalin (fig. 2).

Experiment 17. “Fixation in Carnoy's fluid prevents development of shrunken cells." Fixation in Carnoy's fluid within 1 to 15 minutes after the pressure almost completely prevented the development of shrunken cells. Occasionally, a few shrunken cells were seen in the center of the region of application of pressure (fig. 6 ); one had the impression that such cells were found only where shearing forces had produced minute crevices or ruptures in the tissue. No shrunken cells were found at the parasagittal region and in the opposite hemisphere.

Experiment 18. "Severe tissue damage produces numerous shrunken cells even in tissue fixed in Carnoy's fixative." Experiment 17 suggested that the few shrunken cells observed in the area of pressure resulted from a more severe tissue damage. To confirm a correlation between the severity of damage and the development of shrunken cells in tissue fixed with Carnoy's fluid, a wedge-shaped specimen of cortical tissue was removed. The cut surface was touched with the blade several times and no effort was made to minimize tissue trauma during cutting. The brains were fixed in Carnoy's fixative. The traumatized cortex adjacent to these cuts showed numerous shrunken, hyperchromic cells, which spread over a considerable distance from the cut surface (fig. 7).

The question arose whether these cells were shrunken by the fixative (as suggested by Cammermeyer, '60b) or if they were shrunken osmotically before fixation, as suggested in experiment 9 which showed that such shrinkage can develop in three seconds or less in erythrocytes. If it were pre-fixation osmotic shrinkage, one should be able to restore these cells to normal shape by exposure to a hypotonic medium before fixation; this was attempted in the following experiment. 
Experiment 19. "Cells shrunken after severe injury can be restored to normal volume in a hypotonic medium." A wedgeshaped specimen of cortex was removed in exactly the same manner as in experiment 18: The brains, with their cut surface exposed, were immersed in distilled water for $5,10,15$, and 30 minutes before fixation in Carnoy's fluid. As a result, the entire normal cell population of the cortex was markedly swollen in accordance with experiments 7 and 15 . The traumatized tissue at the cut surface showed that the majority, but not all, of the shrunken cells recovered to approximately normal volume or even a slight swelling (fig. 8). This data showed that it is possible to restore cells to their normal size even after they are shrunken by severe trauma; it also showed that the shrinkage occurred before fixation and not as a result of fixation in Carnoy's fixative. The effect was optimal after about 10 to 15 minutes exposure to distilled water; prolonged exposure did not increase it.

A small fraction of the cells at the cut surface remained shrunken no matter what effort was made to produce osmotic swelling (fig. 8). Such cells usually were found immediately adjacent to the cut surface. It was concluded that their membranes were disrupted by the injury, thus abolishing any possibility of further osmotic volume changes.

\section{DISCUSSION}

The final volume of a nerve cell in a fixed tissue specimen thus will depend on three factors:

(1) The osmolar concentration of the cytoplasm.

(2) The osmolar concentration of the tissue fluid or fixative surrounding the cell.

(3) The type of fixative (preservation or destruction of cell membranes).

Changes due to the first two factors can occur both before and during fixation; however, the fixative determines whether these changes are limited to the period before fixation or can continue during fixation.

Type of fixative. Only a nxative which preserves the semipermeable lipid membranes of cells permits osmotic changes of the cell-volume during exposure to the fixative. Such volume changes of cells can take place rapidly (three seconds or less) upon contact with a hypertonic solution (experiments 5 and 6 ); this seems logical considering the extremely small volume of a cell. If there is a competition between the speed of fixation and the speed of osmotic volume changes, the speed of fixation is relatively insignificant because of the much faster volume changes.

Some fixatives (Carnoy's fixative, trichloracetic acid) damage cell membranes faster than they precipitate the cytoplasm; this is demonstrated by the hemolysis of erythrocytes in Carnoy's fixative (experiment 7) while $95 \%$ alcohol without the addition of acetic acid and chloroform is not so destructive to membranes and thus fixes the cells before the membrane is destroyed (experiment 7). In a block of tissue, a membrane damaging fixative can eliminate the osmotic volume changes (experiment 17) which develop during exposure to formalin (experiment 10). However, it cannot prevent or change volume changes which developed before exposure to the fixative (experiments 9,18 , and 19).

Osmotic concentrations of fixative. Osmotic changes of the volume of nerve cells develop during exposure to hyper- or hypotonic formalin (experiments 8, 10, $11,12,13,14$; also Fortuyn, '24, '27, and Fischer and Ranson, '33; Koenig, Groat, and Windle, '45). This evidences that formalin does not alter the cell membrane in such a way as to pervent shrinkage or swelling of the cell before fixation is completed. Osmotic shrinkage during exposure to the fixative is prevented by Carnoy's fixative (experiment 17) which damages the cell membranes upon contact (experiment 7 ). The shrinkage in formalin is not a specific shrinkage property of formalin as it can be prevented by the addition of acetic acid (experiment 16) which evidently has corrosive action on cell membranes.

Osmotic concentration of the cytoplasm. This factor seems to be the most important one revealed by these experiments. Cells slightly damaged by controlled compression of the tissue behave as if the os- 
molar concentration of their cytoplasm is lowered. These cells are not shrunken after fixation in Carnoy's fixative (experiment 17) or acetic acid formalin (experiment 16). They shrink markedly in isotonic formalin (experiments 10 and 11; also Turner, '03; Cox, '37; Scharrer, '33, '37, '38) and even shrink some in hypotonic formalin (experiment 14). These cells show less swelling than normal cells following exposure to distilled water (experiment 15). The volume difference between the damaged cells and normal cells is reduced (experiment 13) or minimized (experiment 12 ) if the fixative is markedly hypertonic (Fortuyn, '24; Fischer and Ranson, '33).

Severe tissue damage (cut or torn tissue) produces shrunken cells even following fixation in Carnoy's fluid (experiments 17 and 18). Since Carnoy's fixative does not change the volume of cells which were osmotically swollen or shrunken before fixation (experiment 9), it is concluded that the severely damaged cells were rapidly shrunken in the tissue before exposure to Carnoy's fluid. The sample experiments had shown that cells can shrink quite rapidly, in three seconds or less (experiment 5). Such shrinking of cells in the tissue before fixation implies a lowering of the osmolarity of the cytoplasm to an extent which renders the concentration of the normal tissue fluids hypertonic. The osmolarity of liver and kidney cells has been estimated as being about twice that of the intercellular fluid and plasma (Opie and Rothbard, '53); one would expect such cells to shrink if the osmolarity of their cytoplasm is reduced to one-half or less of normal. Since osmotic shrinkage develops rapidly (experiments 5 and 6 ), it is not surprising to observe such shrunken cells even after very brief intervals between tissue removal and fixation (Scharrer, '33, '37, '38; Cammermeyer, '60b) as is well known from the shrunken cells observed in neurosurgical biopsy specimens (Meyer and Meyer, '49). Exposure to distilled water before fixation restores normal volume to the majority of such severely damaged cells (experiment 19). Therefore, these cells shrink osmotically in their normal tissue environment; the shrinkage does not result from the fixation by Carnoy's fixative (experi- ments 18 and 19). A small number of the severely damaged cells cannot be restored with distilled water and it is concluded that the membranes of these cells were disrupted mechanically by the injury; such mechanical disruption, of course, abolishes any further osmotic volume changes.

In conclusion, severe damage produces a severe, rapid decrease of the osmolar concentration of the cytoplasm of nerve cells. Such cells shrink rapidly in their normal tissue environment; they appear shrunken following any type of fixation.

Slight damage results in a minor, probably progressive, decrease of the osmolarity (leaking) of the cell's cytoplasm; such cells do not shrink immediately and do not appear markedly shrunken after fixation with fixatives that destroy cell membranes. Formalin, on the other hand, preserves the cell membrane, and slightly damaged cells with decreased osmolarity shrink in isotonic formalin, while the rest of the cell population remains in osmotic equilibrium. If the concentration of the formalin is altered, the entire cell population does shrink or swell accordingly and the damaged cells follow this pattern but always with more shrinking or less swelling than normal cells.

It seems important to stress the difference between the slight and severe cell damage. Severe damage lowers the osmolarity of the cytoplasm very rapidly, probably to less than one-half its normal value, and corresponding shrinkage develops almost instantly. After slight cell damage, there seems to be a progressive leaking of the cytoplasm which accounts for the increase in the number of shrunken cells with the increased time lapse between damage and fixation (experiments 10, 11; also Fischer and Ranson, '33). Such cells shrink rapidly whenever their osmolarity falls below that of the tissue fluid or fixation fluid respectively.

Comparison with the literature convinces one that most available hypotheses could be either supported or disproven by selecting a group of two or three of our experiments. For example: Cammermeyer ('61) concluded that delicate attachments of the cell membranes to the surrounding tissue are disrupted mechanically by post- 
mortem traumatization of tissue; such cells would shrink due to the shrinking action of the fixative. Experiments 10, 16, 17 , and 18 support this hypothesis; however, it is refuted by the sample experiments with blood and by experiments 10 , 17, 15, and 19: In experiments 10 and 17 , exactly the same mechanical injury applied before fixation produced shrinkage of the damaged cells in formalin but not in Carnoy's fixative, while the tissue, in fact, actually swells in formalin but not in Carnoy's fixative (Merriam, '58). Shrunken cells at the cut surface (experiment 19) could be restored to normal volume by treatment with distilled water preceding fixation in Carnoy; thus, the volume changes developed in the tissue before fixation (experiment 9) and were not due to the fixation. Cammermeyer's studies do not adequately consider osmotic changes. Other investigators (Koenig, Groat, and Windle, "45) demonstrated osmotic volume changes, but one cannot generalize from these findings without considering whether or not a given fixative damages cell membranes. Numerous studies, quoted above, stressed intra vitam or post mortem traumatization of tissue; it has been stated that such cells "shrink" or "collapse," but no precise explanation of the mechanism has been offered. Likewise, the osmotic behavior of such shrunken cells was not analyzed. It is true that perfusion (Cotte, '57; Picard and Cotte, '57) and delayed removal (Cammermeyer, '60, '61b) are optimal means of eliminating post mortem trauma. However, if only parts of the brain are required for examination and if these parts can be exposed with minimal tissue trauma, Carnoy's fixative is preferable because it guarantees that there are no osmotic volume changes of the cells during fixation. These points are of great practical importance, but they do not bear directly on the precise mechanism producing shrinkage of cells. Knowledge of the latter will permit one to design the procedures which fit best any particular experimental project.

When screening the literature for pertinent observations, many publications were found in which hyperchromic cells were described in experimental or pathological material, but not in controls. It was dif- ficult to conceive that all these investigators had produced artifacts by careless handling in their experimental material but not in their controls. Our data suggest that osmotic volume changes during formalin fixation represent a sensitive indicator or reduced osmolarity of the cell's cytoplasm; such osmotic damage can be pathological during life, supravital during removal of the brain, or can occur even during exposure to the fixative. There is evidently no clear-cut borderline between vital and supravital cell damage; decrease of the cytoplasm's osmolarity can develop both in vivo and in vitro. Study of shrinkage artifacts can help us to understand the factors determining the reactivity of cells in the tissue as proposed by Scharrer ('37, '38).

There was no reason to be concerned in our material about the effects of dehydration and embedding in paraffin because all specimens were (many of them simultaneously) subjected to the same treatment. Yet, the appearance of swollen or shrunken cells depended entirely on the manipulations done before completion of fixation (Fortuyn, '27).

Numerous articles report on an increase of certain substances, (e.g., protein) in hyperchromic cells. We have not included these in the discussion since it seemed logical that shrinkage of the cell would be reflected in a relative increase of the solids of the cytoplasm.

Finally, the question as to the cause of the changed osmolarity in the cytoplasm deserves discussion. Potassium is the component in the cytoplasm which is available at highest concentration and which is most susceptible to diffusion out of the cells. Biochemists have spent considerable effort investigating the leakage of potassium from brain slices during metabolic measurements (Dixon, '49a, Aebi, '52). There is also indication that leakage of potassium can occur in vivo during brain damage (Gerard, '38; Dixon, '40). Potassium leakage was observed following anoxia (Dixon, ' $49 \mathrm{~b}$ ) and convulsions (Colfer and Essex, '47). This may hint at a relationship between excessive functional activity and cell shrinkage (Fortuyn, '27); Fedorow ('35), for example, produced identical changes in boutons ter- 
minaux by exposure to hypotonic media and by prolonged stimulation.

Leakage of potassium could explain the puzzling histochemical observation of a very strong reaction for glycogen synthetizing enzymes in shrunken neurons produced post-mortem and no reaction in "normal" neurons (Friede, '59). High concentrations of potassium have been shown to inhibit glycogen synthesis (Kleinzeller and Rybova, '57). It seems logical that leakage of potassium from cells was the common factor removing the inhibition of glycogen synthesis and decreasing the osmolarity of the cytoplasm, thus producing shrunken cells. This mechanism could be of basic importance for the in vivo accumulation of glycogen in nerve cells (Friede, '59). Experimental studies are in progress to investigate the correlation between hyperchromatosis and leakage of potassium from nerve cells.

\section{SUMMARY}

This article reports on a series of $19 \mathrm{ex}$ perimental groups ( 5 experiments each) which help one to understand the precise mechanism of the production of hyperchromic nerve cells; it depends on the interrelation between the osmolar concentration of the cytoplasm and the osmolar concentration of the tissue fluid or fixative surrounding the cell. Seven of these experiments used erythrocytes as samples. The data provides a reasonable interpretation of hyperchromic, shrunken nerve cells.

The volume of a nerve cell in a formalin fixed specimen depends both on the osmolarity of its cytoplasm and that of the fluid surrounding the cell. Increased osmolarity of the latter produces shrinking - and decreased osmolarity swelling - of the entire normal cell population. Cells slightly damaged by local pressure behave as if the osmolar concentration of their cytoplasm is reduced. They shrink in isotonic formalin while normal cells do not; they shrink more than normal cells do in hypertonic formalin; and they swell less than normal cells do in hypotonic formalin. These changes of volume can develop both before and during fixation in formalin since the cell membranes are not immediately damaged by formalin.
Another group of fixatives, including Carnoy's fixative, damages the cell membranes upon contact, as was shown in sample experiments. Osmotic volume changes of nerve cells, therefore, do not develop during exposure to such a fixative, while all osmotic changes which developed in the tissue before exposure to the fixative are preserved. If the cell damage which reduces the osmolarity of the cytoplasm is sufficiently severe, osmotic shrinkage of cells can develop extremely fast before the fixation of the tissue. Erythrocytes were shown to crenate within three seconds or less.

It is suggested that the reduced osmolarity of the cytoplasm of shrunken nerve cells was caused by leakage of potassium from the cytoplasm; such leakage can be pathological in vivo, or can result from artificial, mechanical, postmortem cell damage.

\section{LITERATURE CITED}

Aebi, H. 1952 Zusammenhänge zwischen Atmung, Quellung und Electrolytgehalt überlebender Gewebsschnitte. Helvet. Physiol. Pharm. Acta, 10: 184-192.

Cajal, S. R. 1909-1911 Histologie du systeme nerveux de l'homme et des vertebres. Paris, A. Maloine.

Cammermeyer, J. 1960a Differences in shape and size of neuroglial nuclei in the spinal cord due to individual, regional, and technical variations. Acta Anat., 40: 149-177.

$1960 \mathrm{~b}$ The postmortem origin and mechanism of neuronal hyperchromatosis and nuclear pyknosis. Exp. Neurol,, 2: 379-405. 1961 The importance of avoiding "dark" neurons in experimental neuropathology. Acta neuropath., 1: 245-270.

Cotte, G. 1957 Etude critique de la signification de l'état hyperchromophile des cellules nerveuses. Arch. biol., (Liége), 68: 297-380.

Colfer, H. F., and H. E. Essex 1947 Distribu. tion of total electrolyte, potassium, and sodium in cerebral cortex in relation to experimental convulsions. Amer. J. Physiol., 150: 27-36.

Cox, A. 1937 Ganglienzellschrumpfung im tierischen Hirn. Beitr. Path. Anat,, 980: 399 409.

Dixon, K. C. 1940 Study of cortical metabolism in relation to cerebral disease. Brain, 63: 191199.

1949a Action of potassium ions on brain metabolism. J. Physiol., 110: 87-97.

- 1949b Anaerobic leakage of potassium from brain. Biochem. J., 44: 187-190.

Dolley, D. H. 1910 The pathological cytology of surgical shock. J. Med. Rev., 22; 331-378.

Einarson, L. 1949a Notes on the histochemical aspect of the changes of the spinal motor 
cells in anoxia. Vitamin $\mathrm{E}$ deficiency, and poliomyelitis. Act. Orthopaed. Scand, 15: 5583.

$1949 \mathrm{~b}$ On the internal structure of the motor cells of the anterior horns and its changes in poliomlyelitis. Ibid., 19: 27-54.

Fedorow, B. G. 1935 Essai de l'etude intravitale des cellules nerveuses et des connexions interneuronales dans le systeme nerveux autonome. Trab. Lab. Invest. biol. Mad., 30: 403434.

Fischer, C., and S. W. Ranson 1933 On the co-called sympathetic cells in the spinal ganglia. J. Anat., 68: 1-10.

Flesch, M, 1887 Über die Verschiedenheiten im chemischen Verhalten der Nervenzellen. Mitt. d. Naturforsch. Ges. in Bern Nr, 11691199, 192-199.

Fortuyn, A., B. Drooglever 1924 Changement histologignes dans l'écorce cérébrale de quclgnes rougeurs. Trab. Inst. Cajal. Invest. biol., (Madrid), 22: 67-98.

- 1927 Histological experiments with the brain of some rodents. J. Comp. Neur., 42: 349-391.

Friede, R. L. 1959 Histochemical demonstration of phosphorylase in brain tissue: Association of postmortal neuron changes with phosphorylase activity. J. Histochem.and Cytochem., 7: $34-38$.

Gerard, R. W. 1938 Anoxia and neural metabolism. Arch. Neurol. Psychiat. Chicago, 40: 985-996.

Heidenhein, M. 1905 Trichloressigsaüre aIs Fixierungsmittel. Z. Wiss. Micr., 22: 321-324.

Kleinzeller, A., and R. Rybova 1957 Glycogen synthesis in brain cortex slices and some factor affecting it. J. Neurochem., 3: 45-57.

Kcenig, H., R. A. Groat and W. F. Windle 1945 A physiological approach to perfusion-fixation of tissues with formalin. Stain. Tech., 20; 1322 .

Merriam, R. W. 1958 Standard chemical fixations as a basis for quantitative investigations of substances other than desoxyribonucleic acid. J. Histochem. and Cytochem., 6: 43-51.

Meyer, H., and M. Meyer 1949 Nucleoprotein in the nerve cell of mental patients: A critical remark. J. Ment. Sci., 95: 180-181.

Miller, R. H. 1949 A morphological and experimental study of chromophilic neurons in the cerebral cortex. Am. J. Anat., 84: 201-229.

Nissl, Fr. 1896 Über Beziehungen der Nervenzellubstanzen zu den thätigen ruhenden und ermudeten Zellzustanden. Allg, Z. Psychiat, 52: 1147-1154.

Opie, E. L., and M. B. Rothbard 1953 Osmotic homeostasis maintained by mammalian liver, kidney, and other tissues. J. Exper. Med., 97: $483-497$.

Picard, D., and G. Cotte 1957 Signification de l'état hyperchromophile des cellules nerveuses. Compt. rend. Soc. Biol., 151: 151-153.

Rawitz, B. 1908 Neue Fixier-und Färbemethoden. Z. Wiss. Micr, 25: 385-396.

Sannomiya, N. 1926 Sulfosalisylsäure als Fixerungsmittel. Fol. Anat. jap., 4: 363-374.

Scharrer, E, 1933 Bemerkungen zur Frage der "sklerotischen" Zellen im Tiergehirn. Z. Ges. Neurol. Psychiat., 148: 773-777.

_ـ 1937 Über Ganglienzellschrumpfung im tierischen Gehirn. Beitr. path. Anat., 100: 1318.

1938 On dark and light cells in the brain and in the liver. Anat. Rec, $72: 53-56$.

Turner, J. 1903 An account of the nerve cells in thirty-seven cases of insanity with special reference to those of the spinal ganglia. Brain, 26: $27-70$.

PLATE 1

\section{EXPLANATION OF FIGURES}

1 Experiment 9: Marked swelling of nerve cells and their apical dendrites after exposure to distilled water for 15 minutes and fixation in Carnoy's fixative. $361 \times$.

2 Experiment 10: Shrinkage of nerve cells in the area of local pressure to the cortex and fixation in isotonic formalin. Only a few cells maintain their normal shape. $226 \times$.

3 Experiment 12: Shrinkage of all nerve cells after fixation in hypertonic formalin; the area of pressure cannot be recognized. $226 \times$.

4 Experiment 14: Area of pressure after perfusion with hypotonic formalin (the area is homologous to fig. 2). Numerous cells are shrunken; however, the extent of shrinkage is somewhat less than in figure $2 . \times 361$. 

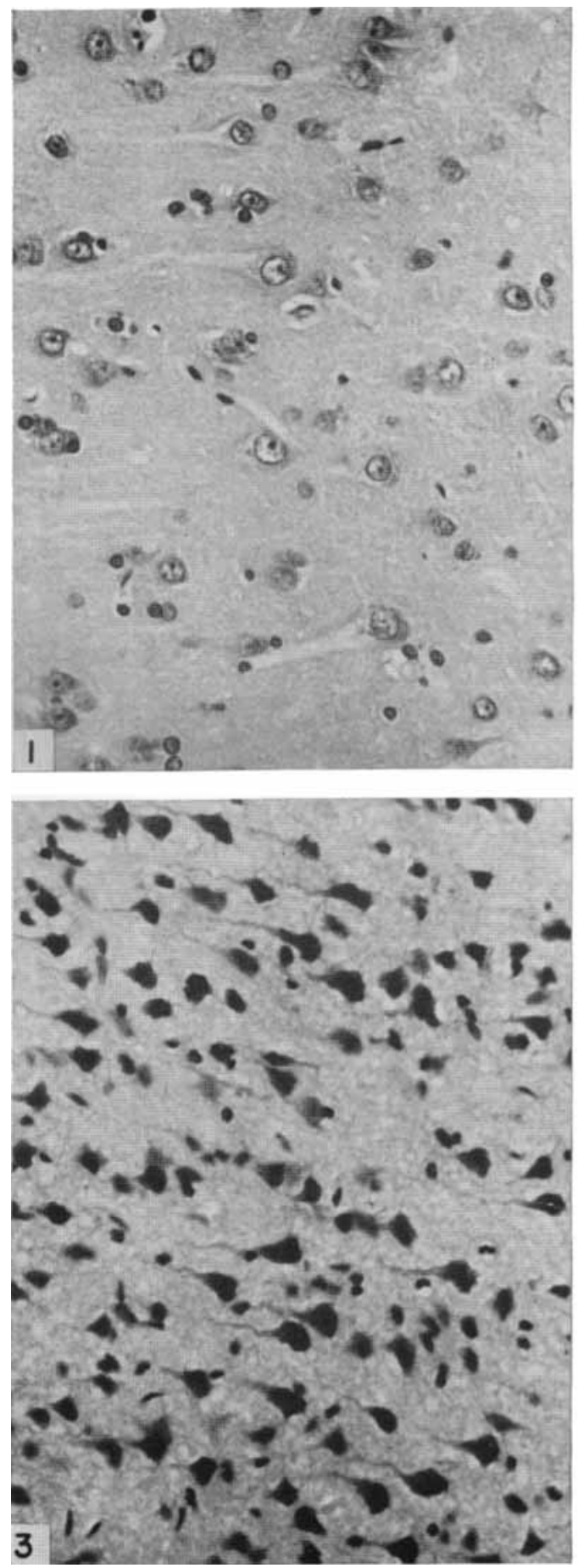

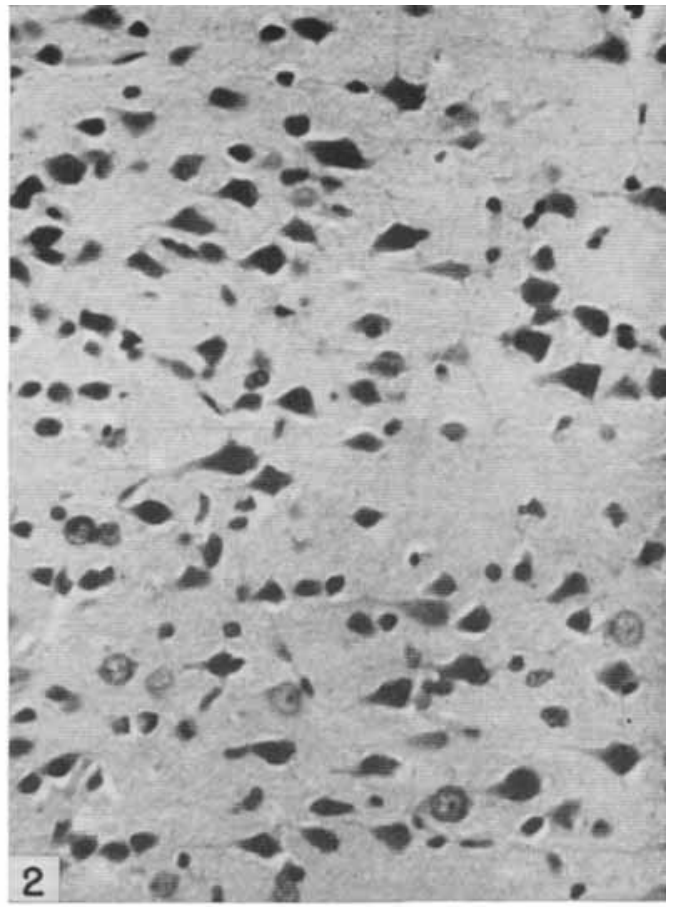

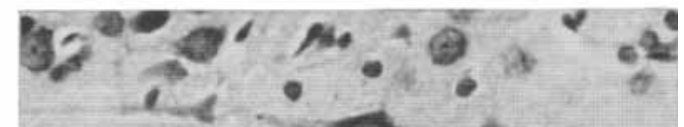

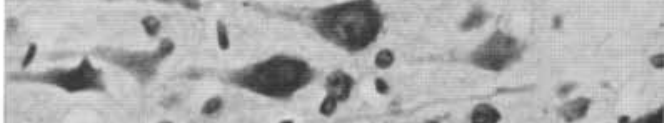

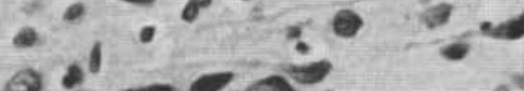

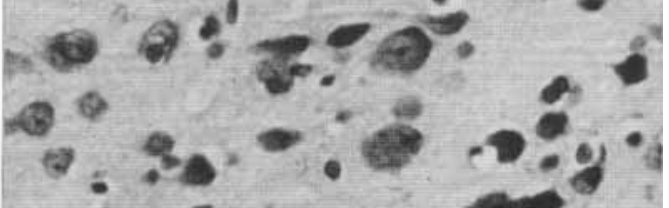

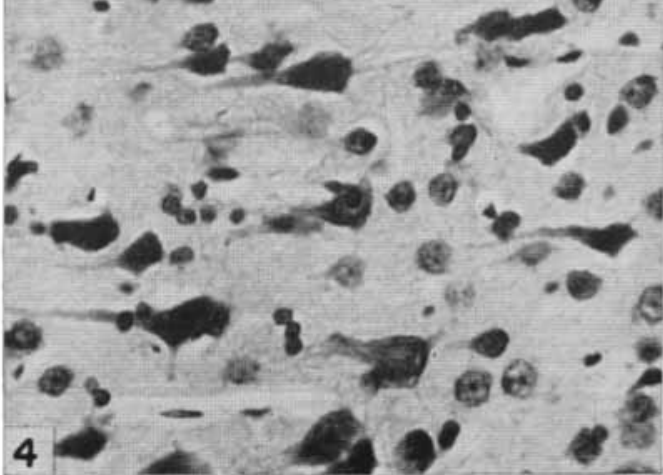


PLATE 2

EXPLANATION OF FIGURES

5 Experiment 16: Area of pressure fixed in acetic acid formalin. The osmatic changes demonstrated in figures 2-4 do not take place in acetic acid formalin. A few cells were shrunken before the application of the fixative (as shown in experiments $9,18,19$ ) $361 \times$.

6 Experiment 17: Area of pressure fixed in Carnoy's fixative; same features as in figure $5,361 \times$.

7 Experiment 18: Fixation in Carnoy's fixative; almost the entire cell population is shrunken due to severe tissue trauma by removing a wedge-shaped specimen of cortical tissue. A few normal cells are seen off the cut surface (left margin of picture). $226 \times$.

8 Experiment 19; Area comparable to that in figure 7; however, this area was exposed to distilled water for ten minutes before fixation in Carnoy's fixative. Most of the cells were restored to approximately normal shape. Adjacent normal cortex showed excessive swelling comparable with figure 1. $226 \times$. 

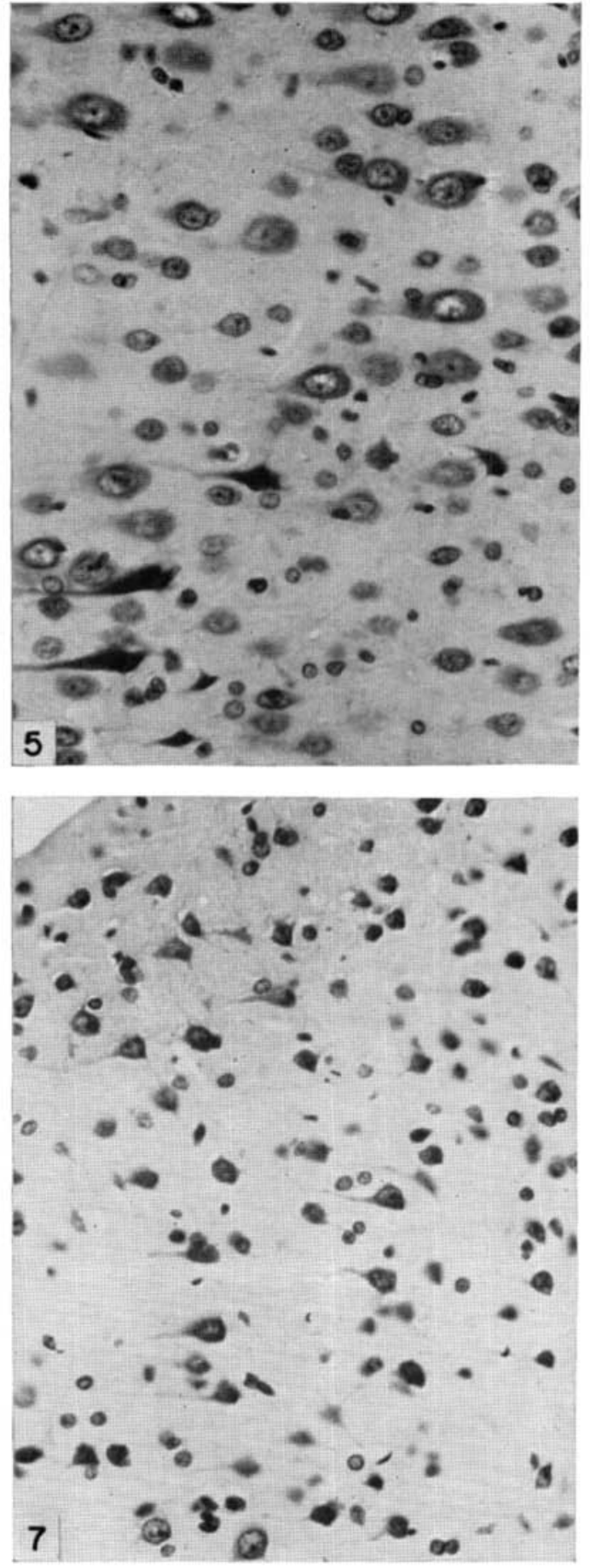

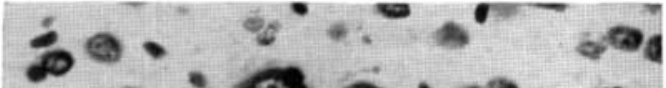

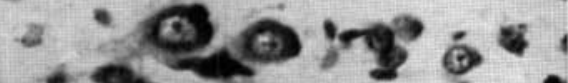

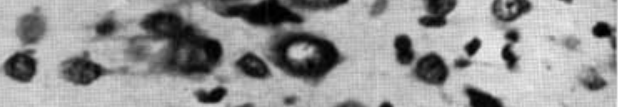

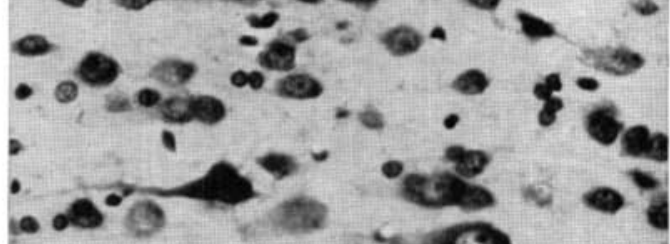

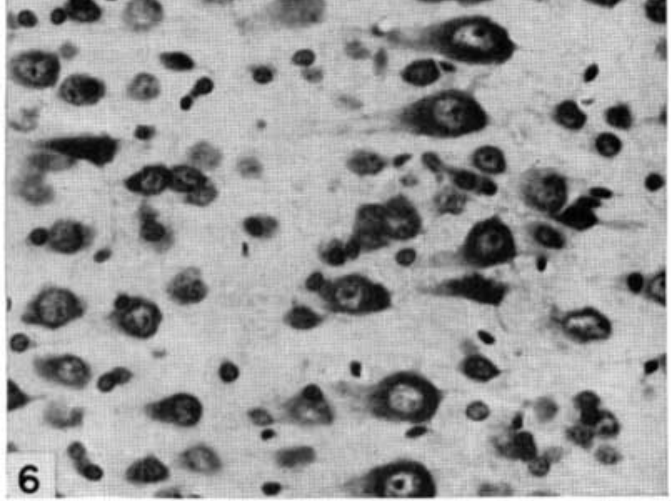

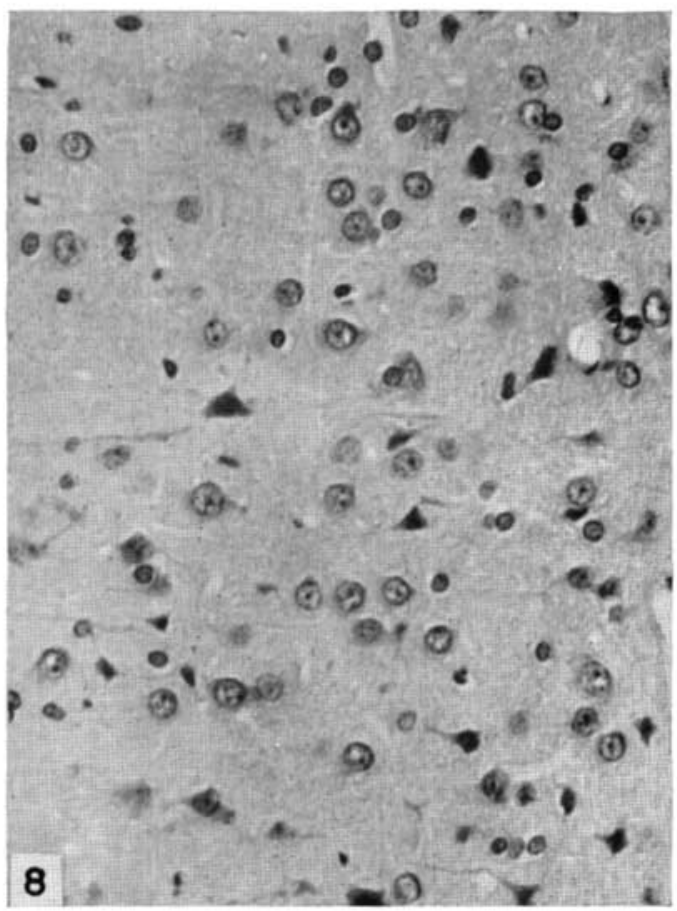

